\title{
Environmental and economic indicators of sustainable development of enterprises of oil and gas complexes
}

\author{
Arif Huseynov ${ }^{1, *}$ \\ ${ }^{1}$ Azerbaijan State Oil and Industrial University, 16/21 Azadliq Ave, Baku, Azerbaijan
}

\begin{abstract}
.
Research background: An indicator system is proposed to determine the nature of environmental and economic sustainability in the oil and gas industry.

Purpose of the article: The main purpose here is based on the experience of developed countries and the safety practices of enterprises, which are widely used in the world as well as in terms of environmental efficiency. This indicator is used to identify the impact of the oil and gas industry on the environment and environmental-economic and social indices.

Methods: Based on various experiences and indices, development and application of indicators is of great importance in terms of development strategies for enterprise formation, elimination of prerequisite in the change of environmental factors, social responsibility and environmental safety. These indicators can be used to establish the environmental rate of the enterprise. Important features of these indicators are their universality, their use in any fuel and energy complex.

Findings \& Value added: Its activity specificity (environmental and economic) is to evaluate the cost of damage. One of its distinctive features is to carry out accounting of the interaction between all environmental and economic character of the enterprise. This experience is already used in the Russian gas industry. Thus, this system demonstrates its applicability in environmental management and optimization of enterprise operation. In Russia, development of significant environmental management of the country in terms of environmental and economic financing, assessment of environmental impact is carried out in accordance with ISA 14000 standards.
\end{abstract}

Keywords: development of enterprises; oil complexes; gas complexes; environmental indicators; economic indicators

JEL Classification: $F 63 ; Q 01 ; P 28$

\footnotetext{
* Corresponding author: ahuseynov@,azfen.com
} 


\section{Introduction}

Fuel and energy resources are a prerequisite for the independent development of each country and the formation of a competitive national economy. However, nature has not provided all countries of the world with fuel and energy resources equally. Therefore, each country and state must determine its fuel and energy resources reliably and for a long-term period, ensuring the formation of a fuel and energy complex including resource potential [1]. For the last 50-70 years, oil and gas have played an important role as major fuel sources in world countries. At the same time, nuclear energy is used. Azerbaijan is one of the few countries that is independently able to cope with this task thanks to the use of existing natural resources by forming its own fuel and energy complex. Azerbaijan has plenty of natural resources, alternative sources of solar energy, oil and gas deposits which allow the country to create a stable fuel and energy balance, as well as the formation of a highly competitive fuel and energy complex. The fuel and energy complex play an important role in improving the welfare of the population thanks to the use of Azerbaijan's natural and national resources. Currently, 71 oil and gas deposits have been opened in the country and most of them are being exploited [2,3].

The current state of the oil and gas industry of Azerbaijan has great prospects among the countries of the world with its natural and economic potential. Azerbaijan's hydrocarbon reserves are still in the focus of world countries. Significant advances in the economic development of Azerbaijan have created technical and economic potential. This development is related to oil and gas reserves and their exploitation. Since the beginning of the last century, up to $50 \%$ of oil and gas reserves have been extracted in Absheron, and since that time, Baku has become an important center of the international oil industry. Existence of nine of the twelve climatic conditions of the world mainly in Azerbaijan has had a great impact on its socio-economic development [4].

However, scientific researches show that drilling and exploitation of new oil and gas wells in our republic is being continued, although this work has been implemented both offshore and onshore for more than 150 years. Thus, foreign investors sign contracts to increase production in the oil and gas sector.

As the fuel energy complex is a consumer of natural resources, it causes environmental pollution. To increase the stability of the complex production of the electrical energy industry, they need to analyze both real and potential threats [5]. The analysis of the economic sustainability of the industrial complex of the electrical power industry is a comprehensive study of its work. This makes it possible to evaluate development trends, identify development trends, develop production targets and reserves, to improve work deficiencies, as well as all performance indicators [6].

There is a need for a comprehensive review of the construction, operation of oil and gas pipelines and protection of the environment, which necessitates environmental and economic research. All these require carrying out environmental and economic studies, studying the impact of pipelines on flora and fauna, atmospheric air, ground and surface water, etc. The construction and operation of oil pipelines and exploitation technology, eliminating the results of oil pipeline accidents, developing calculation technology of environmental damage are a prerequisite by carrying out economic studies [7].

\section{Methods}

The environmental and economic system of the enterprise as well as the interaction system are described below. 


\subsection{Stability limits and factors of ecological and economic systems}

One of the main tasks of determining the level of economic security is diagnostics of business activities to identify deviations from the threshold values and make appropriate management decisions [8]. The movement trajectory of the enterprise management system and its subsequent state will ensure sustainable development or sustainability. These are possible to predict the system sustainability and the management status of the enterprise. Specific algorithms should be developed in this area, which should have extensive database in terms of the enterprise's identification state and development strategy.

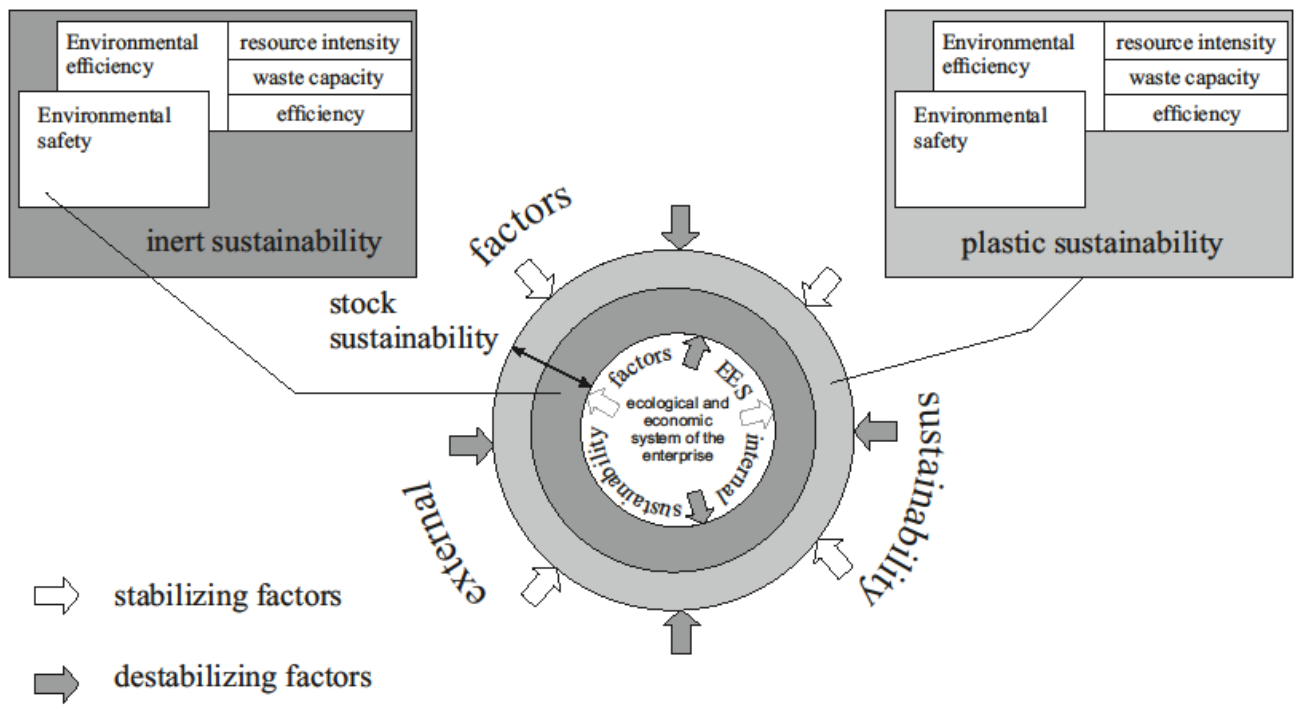

Fig. 1. Interaction of external and internal stability factors

\subsection{Criteria for assessing environmental and economic stability}

Assessment of environmental safety development is an important factor to ensure the sustainability of fuel and energy complexes (FECs). These criteria include total volume of natural resources, system promptness and management of risks in labour protection, industrial safety and environmental management.

Assessment of environmental and economic stability is carried out for the development strategy of the enterprise for environmental purposes, forming its environmental policy, and determining it at a certain period of time. For this purpose, the scope of industrial and economic activities of the enterprise should be taken into account. In addition, the environmental priority and social demographic characteristics of the enterprise should be taken into account.

The internal structure of the enterprise itself shows its environmental and economic stability in terms of several approaches to environmental efficiency and environmental safety as follows:

- a range of activities reflecting the protection of industrial-financial, environmentaleconomic, and natural resources that characterize several social worlds,

- Effective management system, reflecting indicators in accordance with ISO 014000 standards,

- Indicators reflecting people's life activity and current state management.

It can be concluded that indefinite reactions at the middle and high levels of management must necessarily be discussed in both aspects: 
- to achieve the change by describing the long-term performance of an enterprise in order to reach strategic goals,

- demonstrate the performance of the enterprise by analyzing the state and further development of the system, characterizing the stability of statistical indicators.

\subsection{Stable management on the basis of indicator systems}

The environmental data obtained from the environmental and economic diagnostics of oil and gas complex enterprises show that, in addition, it is necessary to analyze the indicators of the enterprise and social environment. The principle of industrial safety refers to the protection of the technological quality of production processes and labour discipline of employees in the case of using management methods to develop the creative potential of employees and ensure the innovative potential of production [9]. Only at this time, such problems as the impact dynamic of the enterprise on the environment, that is, the impact of natural resources on the environment and their polluting the environment with harmful substances should be analyzed the intensity of production processes.

Algorithms that reflect internal factors must be developed to ensure enterprise development. The effectiveness of environmental and economic management is arranged by the specific software. In addition, environmental and economic management is ensured by the use of risk management method. Thus, environmental risk projects are treated in a consistent manner with regard to environmental protection. The most effective way is to minimize them. This also includes a number of technological operations, equipment upgrades, replacement of reagents during drilling and so on. As a result, negative impacts on the environment are required to be eliminated [10].

When analyzing the dynamics of the environmental and economic development of oil refineries, the data obtained from informative indicators facilitates the analysis of future processes [11].

The experience of world countries shows that the funds allocated for ecology should be $5-5 \%$ of the amount allocated for the development of the enterprise. Less reliability of large-scale installations, their destruction, gas pipelines, leakage of toxic liquids and gases from tanks are observed. The production, technological, and marketing components will belong to the same type of safety, namely production and sales, and will be supplemented by indicators of production diversification and rates of renewal and disposal of fixed assets [12-14].

Recently, the facilities, which differ in natural biological processes, are widely used in the field, parameters and physical processes are referred. For this purpose, special attention should be paid to environmental protection in the drilling, development, exploitation of oil and gas wells, which are key areas of oil and gas industry, and during transportation and storage of oil and gas.

\section{Results}

For this purpose, the steady development of the proposed inductors is applied to their universality and the range of activities of various facilities. The characteristic of appropriate impacts (environmental and social payments, the cost of environmental damage, etc.) is considered by taking into account the specificity of the activity (direct impact on the environment).

The features of the indicators create a broad description of the internal relationships between the environmental and economic relations of the enterprise, that is, the interaction between the environmental and economic characteristics of enterprises. 


\section{Discussions and conclusions}

This article presents the environmental and economic data of the enterprise activity based on the modelling of environmental and economic development priorities of enterprises.

This approach is implemented in the management of Russian and Azerbaijani fuel energy facilities. The results were obtained in nature using enterprises and environmental service assessment. It has been used in environmental projects at various levels. In some areas, interim variants must be considered, reflecting a more reliable combination of resource parameters and regulatory options. In essence, this forecast reflects the nature conservation activity.

\section{References}

1. Lebed'ko, A.G., Lebed'ko, G.I. (2015). Forecasting the sustainable development of the oil and gas complex. Studies on Russian Economic Development, 26(2), 151-156.

2. The State Statistical Committee of the Republic of Azerbaijan. (2020). Retrieved from: www.stat.gov.az

3. Pigou, A. (1985). Economic welfare theory. M, Progress.

4. Samadzada Sh.A. (2000). Economic security of economic entities. Baku: Education.

5. Sozontov A., Ivanova M., Gibadullin A. (2019). Implementation of artificial intelligence in the electric power industry. E3S Web of Conference, 114, Art. No. 01009.

6. Zimnukhova D., Zubkova G., Kamchatova E.. (2019). Geothermal energy for heating. E3S Web of Conferences, 114, Art. No. 05002.

7. Lukyanchikov N.N., Chernikov A.N.. (2004). Economic assessment of environmental damage - the basis of the economic mechanism for environmental protection. Moscow, Nature.

8. Pluzhnikov, V., Kukharenko, S., Shikina, S. (2017). The application of multiloop diagnostics model to assess and improve the economic security of enterprises. SHS Web of Conferences, 35(52), Art. No. 01020.

9. Gaisina L.M., Belonozhko M.L., Tkacheva N.A., Abdrakhmanov N.Kh., Grogulenko N.V. (2017). Principles and methods of synergy modeling of management system at oil and gas sector's enterprises. Revista ESPACIOS, 38(33), Art. No. 2017.

10. Mikayilov N.K., Nuriyev J.G., Nuriyeva K.G. (2000). Environmental law. Baku: Law.

11. Kruk, M., Semenov, A., Cherepovitsyn, A., Nikulina, A. (2018). Environmental and economic damage from the development of oil and gas fields in the Arctic shelf of the Russian Federation. European Research Studies Journal, 21(SI 2), 423-433.

12. Islamutdinov V.F., Ustyuzhantseva A.N., (2018). The model to assess economic security of fuel and energy complex enterprises of the northern resource-producing region taking into account the behavioral aspect. International Journal of Mechanical Engineering and Technology (IJMET), 9(8), 1161-1171.

13. Gabrielson P. (2002). Environmental indicators: Typology and overview. Draft update of EEA Technical Report No.251999.

14. Environmental action program for Central and Eastern Europe. (1993). Retrieved from: https://portals.iucn.org/library/node/17886 
15. Tax code of the Republic of Azerbaijan. (2000, July 11). Retrieved from: http://ask.org.az/wp-content/uploads/2018/11/The-Tax-Code-of-the-Republic-ofAzerbaijan.pdf

16. Ways to improve organizational and economic mechanisms of environmental security in Azerbaijan. (2010). Baku, Publishing House of Science. 